\title{
A Review of Particle Image Velocimetry for Fish Migration
}

\author{
S. M. Sayeed-Bin-Asad*, T. Staffan Lundström, A. G. Andersson, J. Gunnar I. Hellström \\ Division of Fluid and Experimental Mechanics, Luleå University of Technology, Luleå, Sweden \\ Email: "sayeed.asad@Itu.se
}

Received 18 February 2016; accepted 24 April 2016; published 27 April 2016

Copyright (C) 2016 by authors and Scientific Research Publishing Inc.

This work is licensed under the Creative Commons Attribution International License (CC BY). http://creativecommons.org/licenses/by/4.0/

(c) (i) Open Access

\begin{abstract}
Understanding the flow characteristic in fishways is crucial for efficient fish migration. Flow characteristic measurements can generally provide quantitative information of velocity distributions in such passages; Particle Image Velocimetry (PIV) has become one of the most versatile techniques to disclose flow fields in general and in fishways, in particular. This paper firstly gives an overview of fish migration along with fish ladders and then the application of PIV measurements on the fish migration process. The overview shows that the quantitative and detailed turbulent flow information in fish ladders obtained by PIV is critical for analyzing turbulent properties and validating numerical results.
\end{abstract}

\section{Keywords}

Particle Image Velocimetry (PIV), Fish Migration, Fishways

\section{Introduction}

Seasonal motion of fish from one area or region to another is known as fish migration. Fish migrate on relatively large time scales ranging from a day to a year or even longer, and in terms of distances starting from some meters to hundreds of kilometers. The primary aim of the migration generally relates to protecting and feeding, reproduction or to escape weather extremes [1]-[13]. Fishes that migrate between fresh and salt water are known as "diadromous fishe". This includes many anadromous species that migrate to fresh water from the sea to spawn and various catadromous species that do the opposite, spawn in the sea and then migrate to freshwater as a juvenile. Some marine fishes like salmon, sturgeon, hilsa, lampreys and different cyprinids follow migration patterns of anadromous, where as eels follow migration patterns of catadromous [14]-[17]. Several issues create migration problems and human made barriers like dams for hydropower plants are one of the main issues [17].

\footnotetext{
*Corresponding author.
}

How to cite this paper: Sayeed-Bin-Asad, S.M., Lundström, T.S., Andersson, A.G. and Hellström, J.G.I. (2016) A Review of Particle Image Velocimetry for Fish Migration. World Journal of Mechanics, 6, 131-149. 
However, for migrating fish at hydropower dams, fishways or fish ladders have often been applied to create passages [18]-[29]. A fishway is an arrangement intended to enable the fish to travel upstream around or over an obstruction [19] [30]-[44]. Fishways can be necessarily even if the height of the blocking structure is as low as $0.3-0.6 \mathrm{~m}$ [45] [46]. There are also some important factors that should be considered to find out the necessity of installing a fish ladder such as the depth of water below the obstruction or the blockage, the height of the obstacle or barrier, the velocity of water flow through or over the obstacle, the quality and quantity of upstream habitant of fish of the obstacle, the movement patterns of fish and the composition of different species within the fish community.

It has been known for a long time that creating various obstacles in rivers like dams for hydropower plants fragment marine ecosystems affects the population of fish. Nowadays, rivers, in the entire world, are being fragmented with hydropower dams and $70 \%$ of the Swedish rivers are exploited for hydropower dams [47] [48]. The fragmentation affects most fish species that need to migrate for spawning like chinook salmon, steel head and lake sturgeon. However, properly designed fishways may dampen the effect on the fish species from the dams.

Engineers need to consider many design factors during planning, designing and placing an obstacle structure in the river. Each obstacle or barrier in any river represents exceptional circumstances and challenges, and therefore, the design and placement of any fishway should be carefully handled. However, there is no perfect fish passage design that can accommodate all fish species at every location. Each fish species has unique physical characteristics which should be considered when designing fishway facilities [49]. Various fish species, for example, trout and salmon are able to swim through very fast water as they have exceptional burst speed while some other fish species such as northern pike, walleye and smallmouth bass are unable to pass through very fast water due to moderate burst speeds. There are some other factors such as energy dissipation, flows, resting areas, entrance locations, attraction velocities, and space in pools which should also be considered carefully when designing a fish passage facility [49].

Thus, the right design of an effective fishway is very important for the safety and improvement of numerous fish stocks and this review has been motivated by how the flow field in fishways can be measured and improved. Main focus is on the application of the flow measurement technique Particle Image Velocimetry (PIV) on the flow in fish ladders or fishways. Hence to start with the next section will review the PIV technology.

\section{PIV Techniques for Fish Migration}

PIV is a non-intrusive laser optical measuring technique used to disclose and scrutinize various flows like turbulent flow, micro-fluidics, spray atomization and combustion processes [50]-[58]. The term PIV was first introduced in the literature in the 1980s [56]. The scientific and technical achievement in lasers, image recording and evaluation techniques, and computing techniques and resources in the last 30 years [56] has enabled PIV to be one of the most versatile experimental tools in fluid mechanics. Grant, Stanislas, Dabiri and Green [54] [59]-[64] have, among others, reviewed the measurement principle and major developments of PIV reported in many research articles and Raffel et al. (2007) [65] have authored a comprehensive book on the technique. Since the flow in fish ways is generally complex, PIV is an appropriate experimental technique to obtain the velocity field.

PIV tracks the pattern of tracer particles seeded in the fluid to get the entire velocity field of the given area of measurement. A modern PIV system consists of several components and the main ones are an object to do measurements on, a multi-pulsed laser system, one or more digital cameras synchronized with the lasers and a computer to manage the entire system and analyze the data [66]-[70]. Standard 2D-PIV (2D2C) is used to measure two components velocity in one plane with one camera whereas Stereo-PIV (2D3C) is used to measure three components velocity in one plane with two cameras. Recently another type of PIV system has become commercially available that uses more than three cameras which is known as a tomographic PIV system [71]. Due to the expensive price and complicacy in experimental setups, the most commonly used PIV to disclose the flow in fishways is still 2D2C PIV. The basic setup of a 2D2C PIV system is shown in Figure 1. The key technologies of a typical PIV system will be briefly discussed hereinafter.

\subsection{Illumination System}

Double-pulsed Nd:Yag lasers are the most widely used illumination system in fish migration experimental studies because these lasers can emit mono-chromatic light with high density energy. Thin light sheets may be formed 


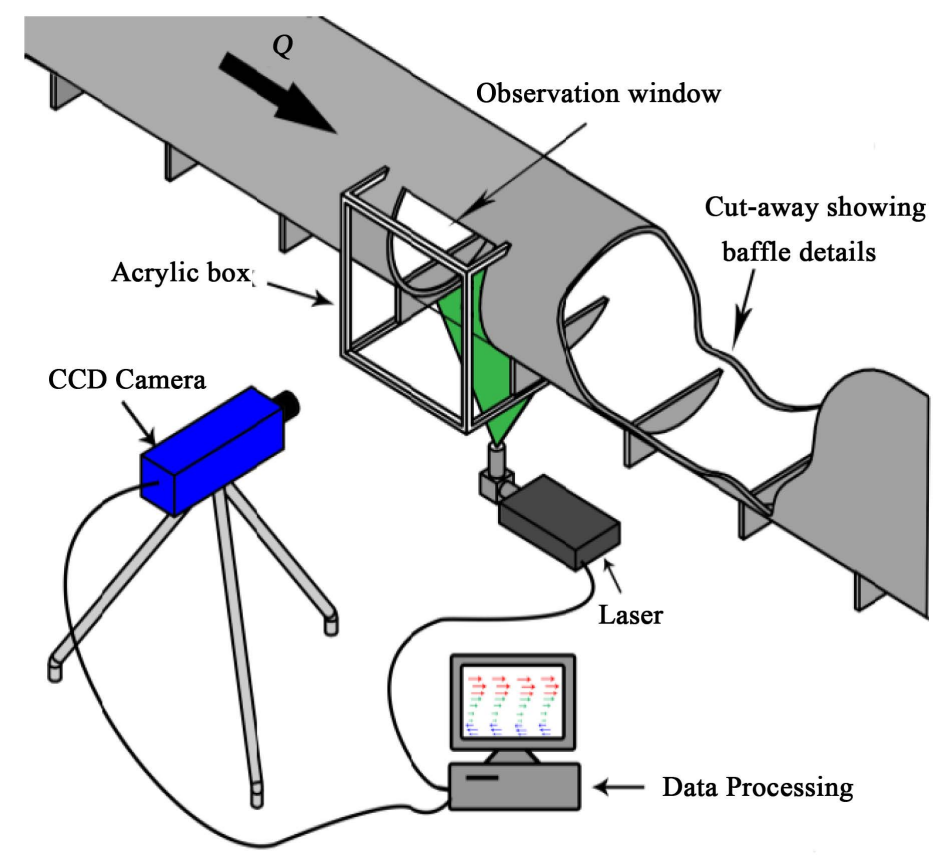

Figure 1. Representation of a 2D-2C PIV measuring arrangement. Photo courtesy of Dr. Mohanad A. Khodier [72].

to illuminate and record patterns of the tracing particles with no chromatic aberrations. Double-pulsed Nd:Yag lasers usually have an articulated delivery arm for generating a green light sheet with a $532 \mathrm{~nm}$ wavelength. The light sheet optics is placed at the end of the articulated delivery arm that can be placed at any angle to produce the thin light sheet. Typically, one or more cylindrical lenses are used to adjust field angle and thickness of the laser light sheet. The light sheet thickness in the measurement area is usually about $1-3 \mathrm{~mm}$ but can be even thinner [73]-[76]. However, using such a thin light sheet as the illumination method also brings about a challenge for measuring a strong three-dimensional flow field. In this case, many particles recorded by the cameras in the first frame may move out of the measured plane and cannot be captured in the next frame. That will limit the accuracy of the PIV measurement to the regions of the thin plane flow [77]. For this reason, an important parameter to set when using lasers as the illumination source is the delay in time between the pulses, $\Delta \mathrm{t}$. This time delay should be long enough to enable accurate measurements of the displacement of the pattern of the tracer particles between the two pulses, but also need to be short enough to minimize the number of particles moving out from the light sheet between subsequent illuminations.

\subsection{Image Recording Devices}

Coupled charged devices (CCD) cameras and complementary metal oxide semiconductor (CMOS) cameras are the commonly used image recording devices for flow measurements in fish migration. CCD cameras are the most widely used image recording devices in PIV experiments for their high spatial resolution, convenient data transmission and image processing, minimum exposure time, high light sensitivity at $532 \mathrm{~nm}$ and low background noise [78]-[81]. A CCD element is, generally, an electronic sensor converting photons into electrons [82]. A sensor of the CCD camera usually consists of an array of many individual CCD elements, which are also called pixels. Today, commercially available CCD cameras typically have the sensor resolution range from $2 \mathrm{M}$ pixels $(1600 \times 1200)$ to $29 \mathrm{M}$ pixels $(6576 \times 4384)$, and the corresponding frame frequency from $35 \mathrm{~Hz}$ to $2 \mathrm{~Hz}$ [83]. Thus, there should be a trade-off between the spatial and temporal resolution, and the CCD cameras should be selected based on the specific applications. For example, a high resolution CCD camera is necessary for large-scale measurement areas, which aims to obtain the complete flow structures. Contrarily, a high frequency CCD camera is more suitable for studying small-scale turbulent characteristics of fluid flows. The dynamic range of CCD sensors should also be considered to evaluate the signal quality per pixel. Normally, a dynamic 
arrange of 8 or 10 bits data output per pixel is sufficient for most PIV purposes. However, with usage of advanced cooling technique, 14 or 16 bit cameras are also available for applications such as planar laser-induced fluorescence (PLIF) where very low noises and high dynamic range are required.

For time-resolved measurement acquiring accurate turbulent information a high-speed CMOS camera should be used rather than a CCD camera. High-speed recordings based on recently developed CMOS sensors can even be used to capture the frequencies in the kilo-Hz range. This is very promising for studies of turbulence. Such a CMOS sensor also allows recording and handling of up to some thousand frames per second at a satisfactory noise levels. The trade of is the sensor resolution. Though, as a more advanced image recording technique, the low spatial resolution has become the main obstacle for CMOS cameras to completely replace the CCD cameras. This critical drawback limits the applications of CMOS cameras only to small-scale measurements. Thus, CCD cameras are still the main image recording devices for PIV measurement currently due to the better image quality and wider applied range. Hain et al. [81] reported a detailed comparison between CCD cameras and CMOS cameras.

\subsection{Seeding Particles}

The result from PIV measurements is heavily dependent on the seeding particles doped into the fluid flow to disclose the velocity field. The accuracy of the velocity field depends on seeding particles capability to follow the instantaneous movement of the uninterrupted phase. The selection of the most favorable diameter of the tracer particles is a negotiation between a quick response of the tracer particles in the fluid, needing tiny diameters, and a high SNR (signal-to-noise ratio) of the particle images, requiring large diameters. This was stated by Melling (1997) [84] who reviewed the use of different seeding particles during PIV measurements. The specifications of the tracer or seeding particles were compared to the characteristics of the scattered light as well as the capability of aerodynamic tracking.

Properties of the Tracer Particles

The scattering characteristics of the particles can be expressed with the following equation:

$$
C_{s}=\frac{P_{s}}{I_{o}}
$$

where, $C_{s}$ is the scattering cross-section, $P_{s}$ the ratio of the total scattered power and $I_{0}$ the laser intensity. Figure 2 shows the alteration of $C_{s}$ as a function of the particle diameter $d_{p}$ to the wavelength of the laser $\lambda$ for spherical particles at a refractive index $m=1.6$. The comparison of the approximate $C_{s}$ for a diatomic molecule and two larger particles is shown in Table 1. It is clear that larger particles can give exponentially stronger light signals, which relate to the larger measuring area and higher signal-to-noise ratio.

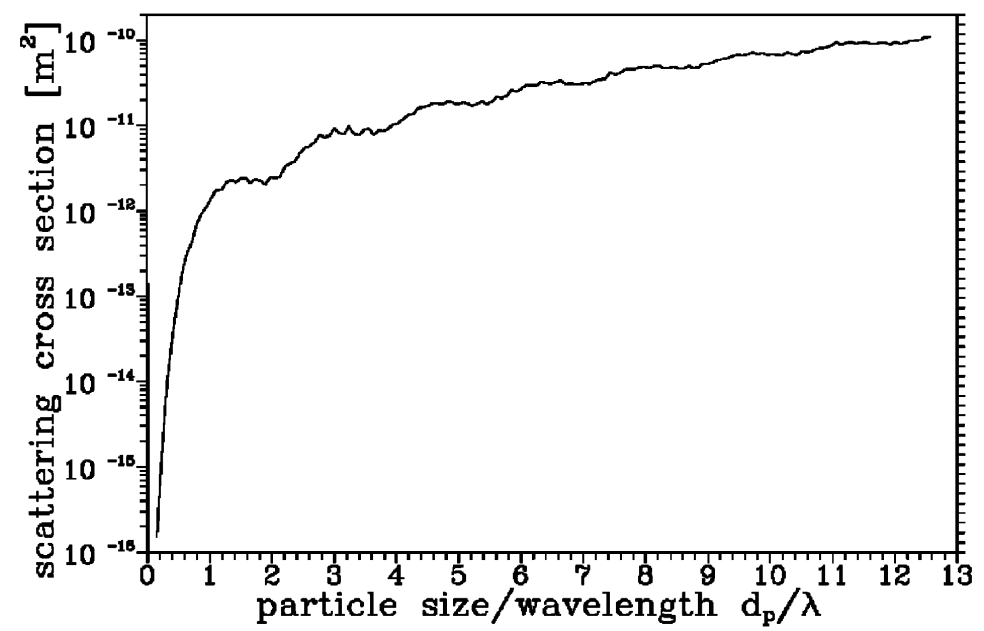

Figure 2. The scattering cross section as a function of the particle size $m=1.6$. From [84], reproduced with permission from the Journal of Measurement Science and Technology. 
Table 1. The scattering cross section as a function of particle size. From [84], reproduced with permission from the Journal of Measurement Science and Technology.

\begin{tabular}{ccc}
\hline$d_{p}$ & & $C_{s}$ \\
\hline Molecule & & $\approx 10^{-33} \mathrm{~m}^{2}$ \\
$1 \mu \mathrm{m}$ & $C_{s} \approx\left(d_{p} / \lambda\right)^{4}$ & $\approx 10^{-12} \mathrm{~m}^{2}$ \\
$10 \mu \mathrm{m}$ & $C_{s} \approx\left(d_{p} / \lambda\right)^{2}$ & $\approx 10^{-9} \mathrm{~m}^{2}$ \\
\hline
\end{tabular}

The tracking of tracer particles is particularly crucial for PIV measurement accuracy. The tracking ability depends on the particle shape, particle density, fluid density and the fluid viscosity. To summarize, the size of the tracer particles should be optimized to balance between the tracking behavior and the scattering characteristics. Melling (1997), Willert et al. (2007) and Bosbach et al. (2009) [84]-[87] reveal more details about the properties of the tracer particles.

\subsection{Image Evaluation Methods}

It is obvious from the working principle of PIV that the technique is to measure directly two basic dimensions, displacement, and time. However, it is impossible to calculate the velocity for each particle due to the high concentration of particles used and overlaps between particles in captured images. Therefore, image evaluation methods are necessary to derive the displacement information from raw particle images. The preferred evaluation method in PIV is to capture two images on two separate frames, and perform multistep cross-correlation analysis, hence the displacement of patterns of particles is derived. This cross-correlation function has a significant peak, providing the direction and magnitude of the velocity vector without ambiguity. The correlation methods are commonly based on digital fast Fourier transform (FFT) algorithms for calculating the correlation functions. For fish migration applications, the recently most widespread used evaluation method is adaptive correlation. The adaptive correlation technique [88] iteratively determines velocity vectors using an initial interrogation area (IA) of the size $N$ times the final IA size and employs the intermediary information as results for the next smaller size IA, until the final size of IA is reached. The IA is a sub-area in the recorded images and its dimensional setting directly determines the spatial resolution and accuracy of the measurement. The smaller IA size and higher overlap ratio can achieve higher spatial resolution, but require higher quality image recordings and consume longer computing time. According to the reviewed papers, the size of the IA is typically set to be $32 \times 32$ pixels or $64 \times 64$ pixels with overlaps of $50 \%$ or $25 \%$ for PIV applications.

In addition, the adaptive correlation method can achieve higher accuracy supplemented with high sub-pixel accuracy and adaptive deforming window algorithm. Currently, adaptive correlation is available in most of the commercial PIV software packages. Adaptive PIV interrogation [88] [89] is a more advanced and automatic correlation algorithm for determining velocity vectors of particle images. This technique iteratively amends the shape and size of the IA for adapting to local density of tracer particles and gradient of flow. The method also includes options to apply window functions, frequency filtering as well as validation in the form of universal outlier detection [90]. In general, adaptive PIV can achieve higher accuracy and spatial resolution results than adaptive correlation but consumes much more computing resources. Another advanced evaluation method having potential for fish-way channel applications is 2D or 3D least squares matching (LSM) [91] [92]. Compared with available correlation based methods, LSM is a gray-level tracking technique which performs translation, deformation and rotation of the IA [91]. The algorithm of LSM iteratively contrasts gray-level tracking of an IA between the first time step and the second time step. This is an iterative least squares procedure applying affine transformations on the IAs. Thus, LSM can not only yield the zero order translational velocities just like the correlation methods, but also simultaneously take the first order terms of fluid motion into account. For this reason, the velocity gradient tensor, the deformation tensor and the rotation tensor can accurately be derived with LSM, without any assumptions and manipulations. However, the LSM has received much less attention than correlation methods due to much longer computation times and requirement of extremely high quality particle images. Though having distinct advantages, the two advanced methods have been less used to evaluate data from PIV experiments. Nevertheless, these methods have great potentials for the fine measurement of complex flow, where larger velocity gradient tensor exists and greater accuracy is desired. Though there are a number of 
algorithms available, there is not a single algorithm that has the best performance everywhere [61]. Detailed analyses of the performances of the state-of-the-art evaluation methods are available in the main results of the PIV challenges presented in [60]-[62].

In summary, a variety of techniques is involved in a flow field evaluation with PIV. However, no universally applicable PIV system is available for different applications. In practice, many compromises and decisions need to be made from case to case. Close attention should be paid to the selection of appropriate PIV system parameters for their specific needs, such as the measuring area, the temporal and spatial resolution and the required precision. The above overview does not include the principles for three dimensional PIV techniques, such as stereoscopic PIV, topographic PIV and defocusing PIV [93], because these techniques have only occasionally been applied for fish migration as will be exemplified in the next section

\section{Application of PIV in Flow Field Measurement in Fish Migration}

A number of cases where PIV has been used to measure flow fields connected to fish migration are presented in this section. The review is mainly focused on publications in English language journals during the latest years and is not inclusive but represents the status and trend of the PIV applications in fish migration.

Mohanad A. Khodier (2012) [72] studied turbulent flow characteristics of the flow through a fishway both experimentally and computationally. PIV was used to measure the turbulent flow characteristics in a pipe (Figure 3(a)) having length of $18.3 \mathrm{~m}$ and a diameter of $0.57 \mathrm{~m}$. the pipe was made of high-density polyethylene (HDPE) [94]. Since this polymer is not optically transparent, an observation window was positioned in the middle of the pipe consisting of a transparent lexan sheet. The PIV system used to measure the flow field, consisted of a CCD camera with a $1376 \times 1040$ pixels resolution and a Nd:YAG laser with light sheet optics to illuminate the area of interest. With the PIV system accurate, undistorted velocity vector data could be produced as exemplified in Figure 3(b).

The flow field was measured for several flow rates as exemplified in Figure 4. The measured shear stress was subsequently calculated with the following equation:

$$
\tau=\mu \frac{\partial U}{\partial y}
$$

It is noted that the PIV system produced the velocity field accurately and then the shear stress (velocity gradient) was derived for every flow situation.

Green et al. (2011) [95] conducted PIV experiments in a flume with a submerged smaller channel with an obstacle designed to increase the velocity downstream of the so called attraction channel, shown in Figure 5. Different designs of obstacle and channel were tested to find the best fishway configuration that maximizes attraction of fish. A two dimensional PIV system from LaVision GmbH was applied [96]. The system consists of a dual pulsed laser (Nd:YAG) with maximum $100 \mathrm{~Hz}$ repetition rate for illumination of the flow area and a FlowMaster Imager Pro CCD-camera from LaVision [97] having a $1280 \times 1024$ pixels spatial resolution per frame. They also used a 3-Axis Traverse System [98] to enabling a repositioning of the laser and camera in all

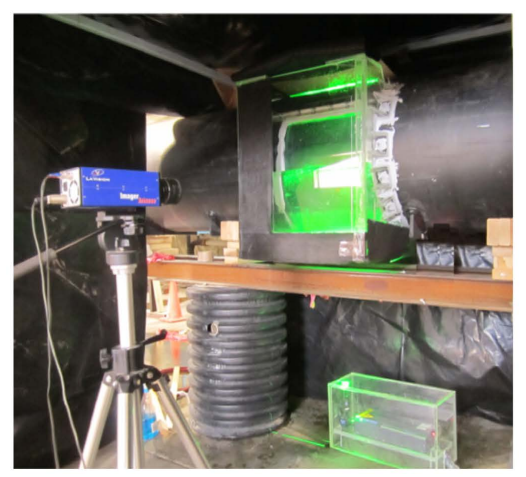

(a)

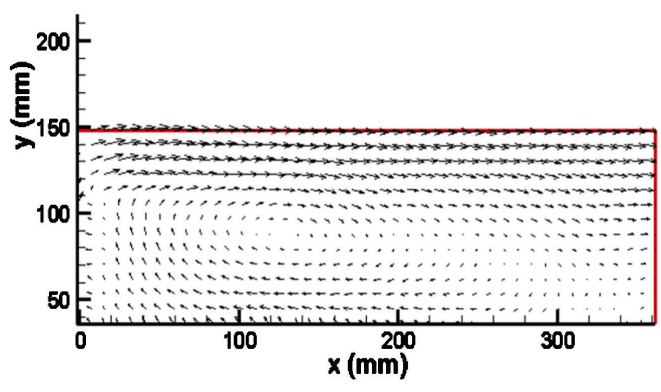

(b)

Figure 3. PIV measurements of fish way (a) PIV setup at the Water Research Laboratory at Utah State University (UWRL). (b) Velocity vectors. Photo courtesy of Dr. Mohanad A. Khodier [72]. 


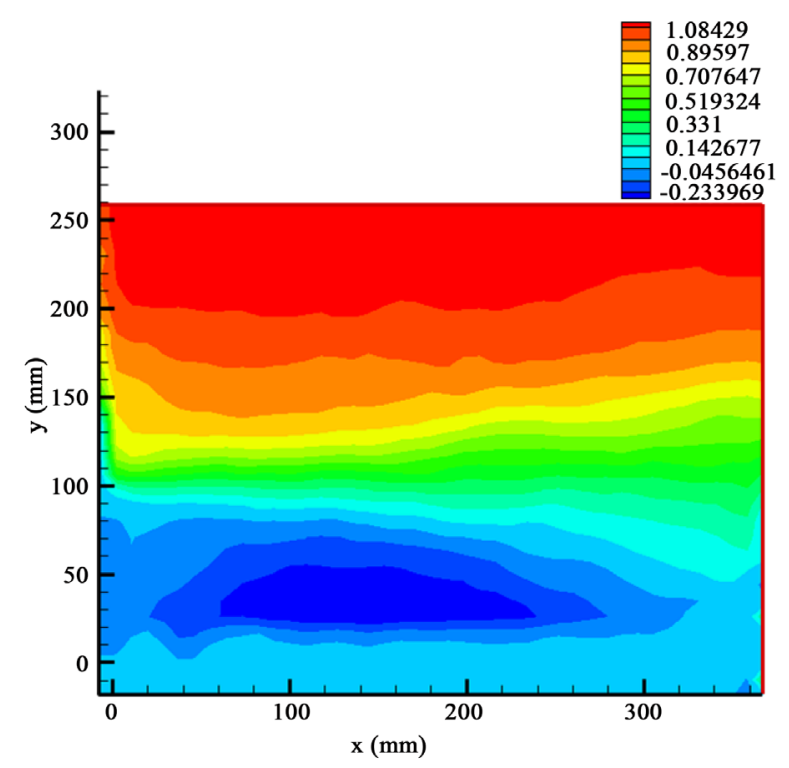

(a)

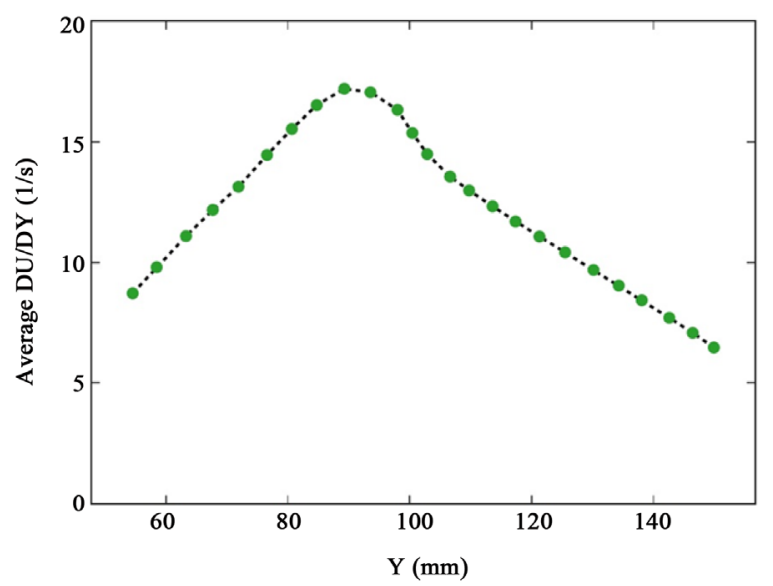

(b)

Figure 4. (a) Velocity contour (b) Velocity gradient for a flow rate, $Q=85.0$ l/s. From [44], reproduced with permission from Dr. Mohanad A. Khodier.

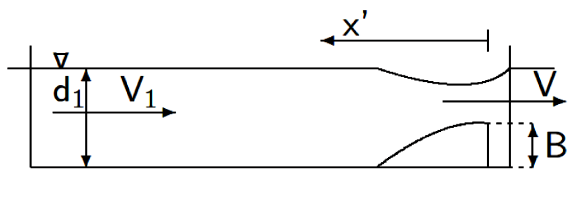

(a)

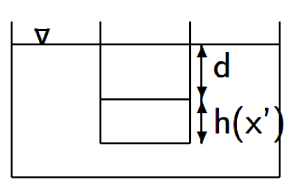

(b)

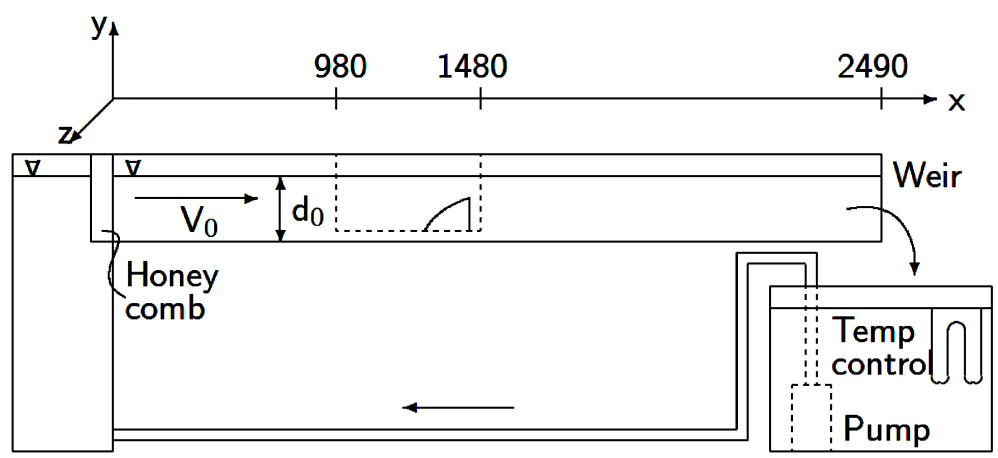

(c)

Figure 5. Schematic representation of the experimental setup. (a) The attraction channel with the ramp; (b) Cross-section of the water flume and attraction channel; (c) The flume as seen from the side. From [95], reproduced with permission from the John Wiley and Sons.

three (x, y and z) directions up to a length of $500 \mathrm{~mm}$. The tracer particles used [65] were hollow glass spheres with a $6 \mu \mathrm{m}$ diameter from LaVision $\mathrm{GmbH}$. A constant velocity, $0.2 \mathrm{~m} / \mathrm{s}$, was maintained in the fish ladder channel and a $1400 \mu$ s time separation between laser pulses was applied. The laser repetition rate was kept constant to $50 \mathrm{~Hz}$ and every measurement had 250 image pairs. Figure 6 illustrates the PIV measured flow fields at different location of the attraction channel. These PIV results exposed that the flow pattern is affected by rather minor tilting of the attraction channel from the original flow direction.

Tarrade et al. (2011) [76] used PIV for experimental studies of hydrodynamic turbulent flows generated in vertical slot fishways at Institut Pprime of the University of Poitiers (France) where they mainly characterized 


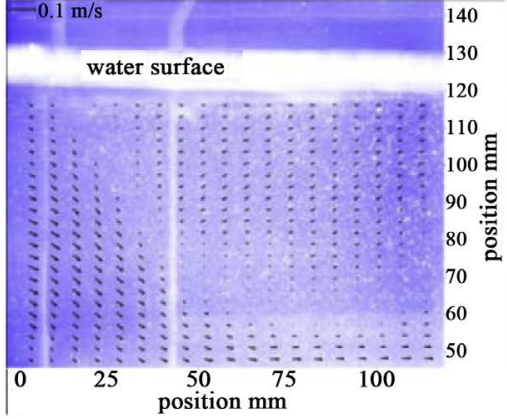

(a)

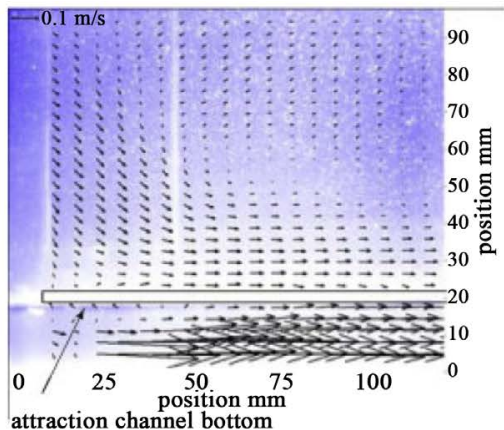

(d)

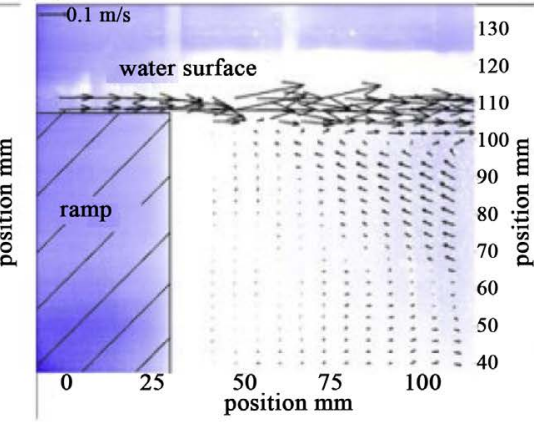

(b)

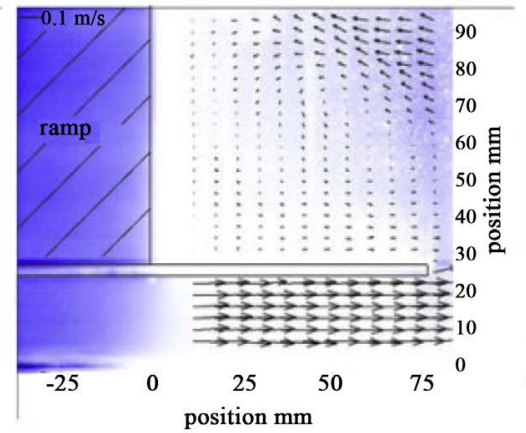

(e)

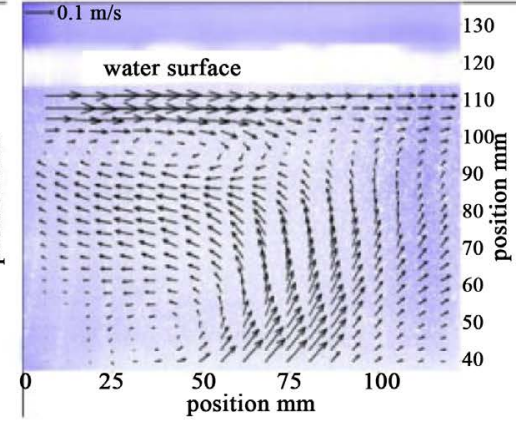

(c)

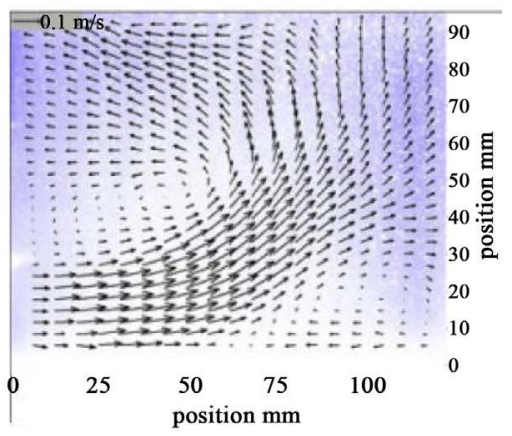

(f)

Figure 6. Flow fields at various location of the attraction channel measured by PIV. From [95], reproduced with permission from the John Wiley and Sons.

some kinematics flow parameters, such as, mean velocity, the kinetic turbulent energy, the vorticity and the instationary nature of the flow for several slopes and flow discharges using two different types of geometries. A 2C2D PIV from LaVision was used for visualizations and two-component flow velocity measurements. This PIV-system consists of two CCD cameras with a resolution of $1600 \times 1200$ pixels and an Nd-Yag laser (Spectra-Physics, $180 \mathrm{~mJ} /$ pulses) generating a $1.5 \mathrm{~mm}$ thick laser sheet. The laser sheet illuminated hollow glass particles with $d_{p}=20 \mu \mathrm{m}$ and a CCD camera was used to visualize the entire pool flow through a $45^{\circ}$ mirror as shown in Figure 7.

The PIV measurement resulted in two different patterns of turbulent kinetic energy and vorticity for different geometrical configurations as shown in Figure 8.

Tritico et al. (2010) [99] studied the effect of flow characteristics on fish swimming speed and stability during migration. The main characterization was the eddy composition being described by the eddy diameter $\left(d_{e}\right)$, the eddy vorticity $\left(\omega_{\mathrm{e}}\right)$ and the eddy direction, meaning horizontal or vertical. PIV experiments were conducted using a flow visualization water flume with a test section being $0.25 \mathrm{~m}$ in length, $0.60 \mathrm{~m}$ in width and $0.55 \mathrm{~m}$ in height as shown in Figure 9. The portable PIV-system used has a $532 \mathrm{~nm}$ wavelength laser, a $90 \mathrm{~mW}$ battery power and a black and white 10-bit CCD-camera having a resolution of 1 megapixel. The PIV measurements revealed that the habitat selection of fish, fish migration, and fish swimming stability are influenced by turbulent eddies.

Deng, Z. et al. (2004) [100] used high-speed PIV to study flow characteristic around fish. A two-dimensional digital PIV (DPIV) system was used with an LDP diode-pumped Nd:YAG pulsed laser having capability of producing an average power of 15 watts at a wavelength of $532 \mathrm{~nm}$ at $1000 \mathrm{~Hz}$. A negative lens of cylindrical shape was employed to spread the laser beam into a sheet of $220 \mathrm{~mm}$ in the $x-y$ measurement plane and the sheet was focused with a positive spherical lens to a waist close the midpoint of the test area. The thickness of this laser sheet was approximately $0.8 \mathrm{~mm}$ for a field of view of $220 \times 220 \mathrm{~mm}^{2}$. As seeding particles glass spheres with $d_{p}=70 \mu \mathrm{m}$ and a density of $1180 \mathrm{~kg} / \mathrm{m}^{3}$ were used. A Photron 1280 PCI high-speed, high-resolution digital camera [101] was employed to record the images. This camera uses a 10-bit CMOS sensor with a global electronic shutter as fast as $7.8 \mu$ s and a sampling rate of 500 frames-per-second at a resolution of $1280 \times$ 


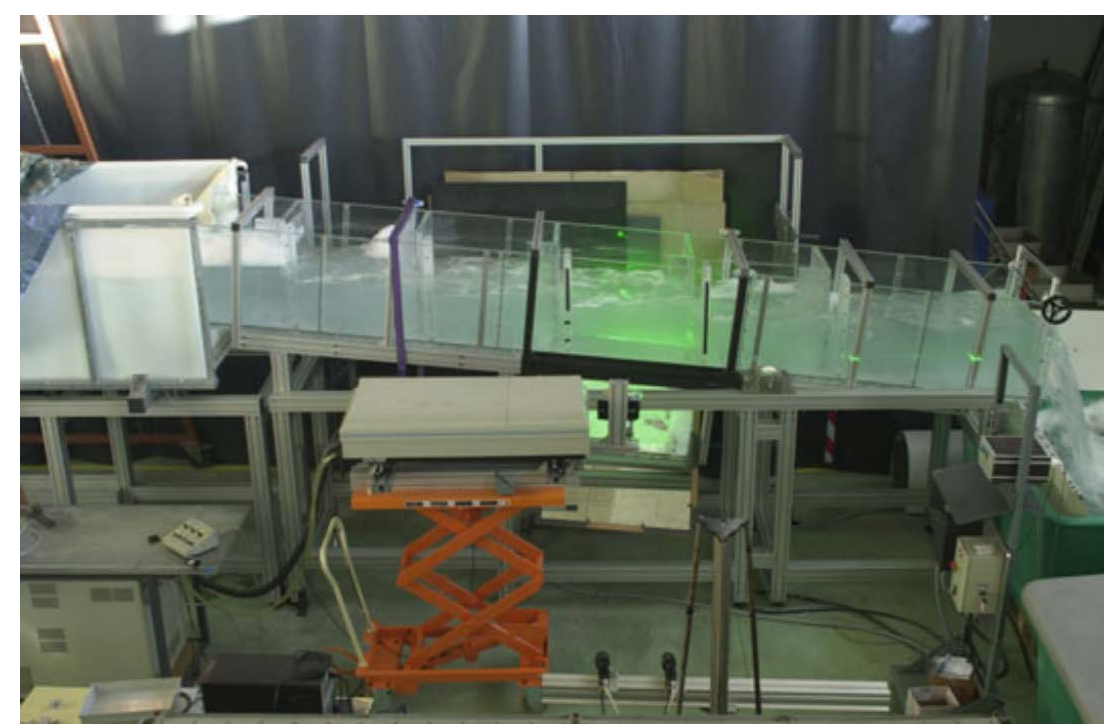

Figure 7. Experimental arrangement. From [76], reproduced with permission from Springer.

$$
\sqrt{\frac{T K E(\vec{x})}{U_{0}}}
$$

$$
\frac{\overline{\omega(\vec{x})}}{U_{0} / b}
$$

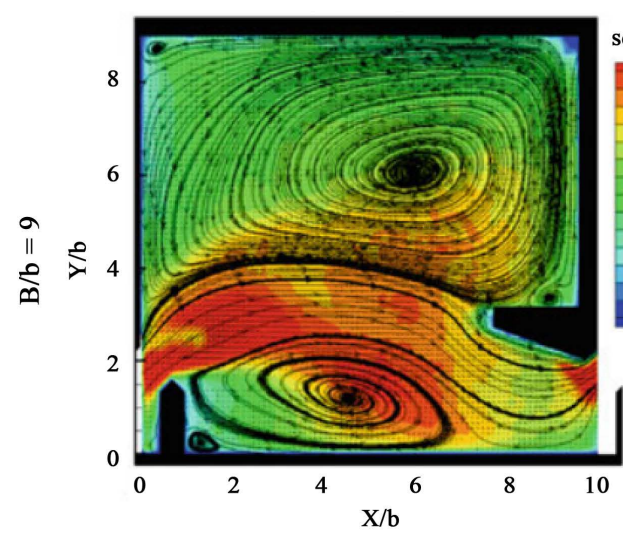

(a)

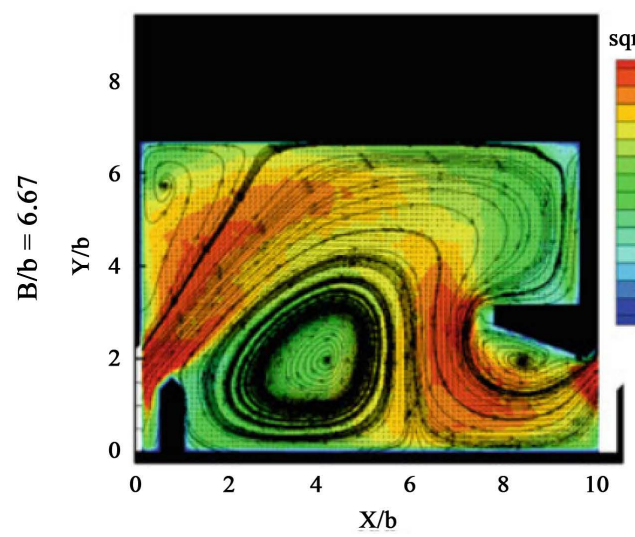

(c)

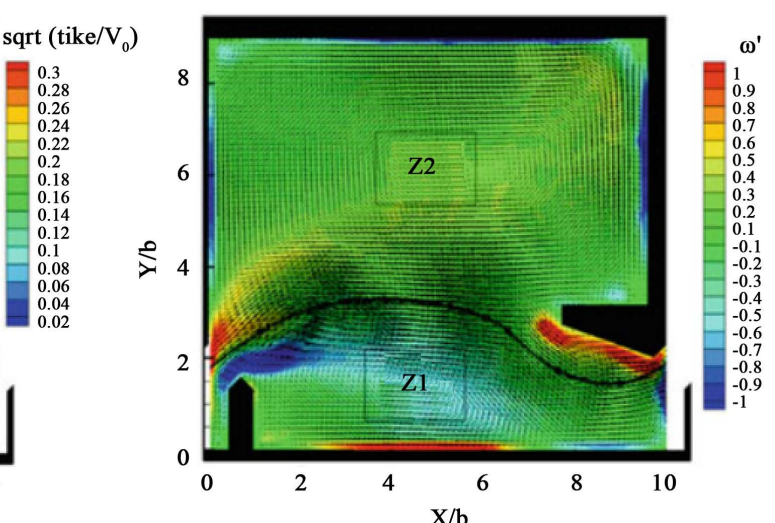

(b)

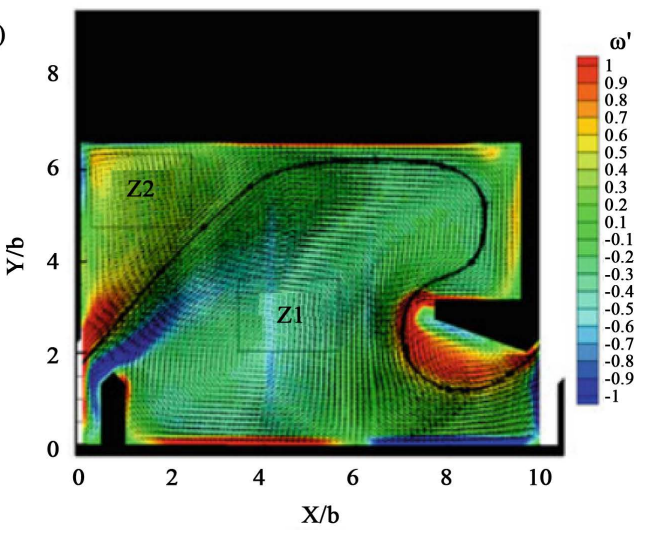

(d)

Figure 8. Turbulent kinetic energy ((a) \& (c)) and vorticity ((b) \& (d)) for different geometries, $S_{0}=10 \%, Q=$ $0.023 \mathrm{~m}^{3} / \mathrm{s}$. From [76], reproduced with permission from Springer. 


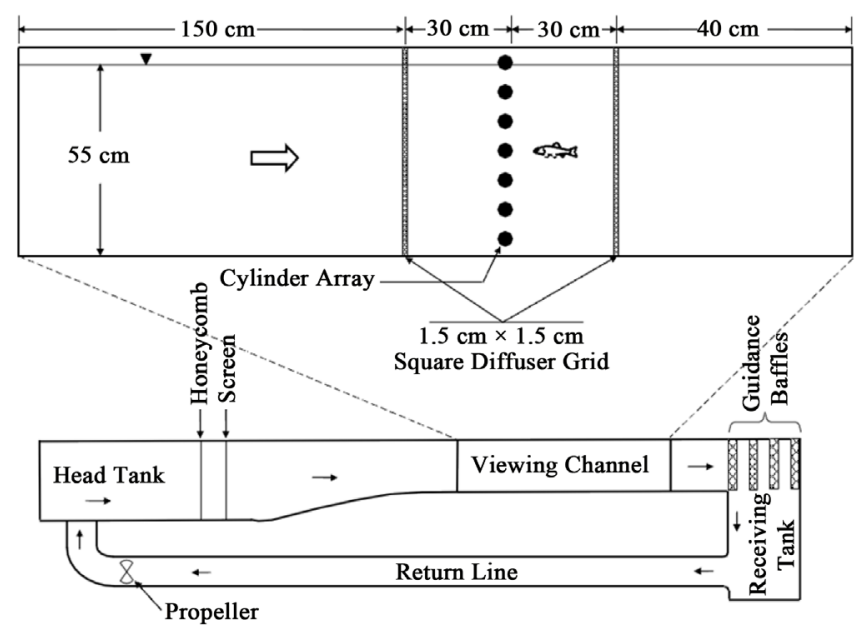

(a)

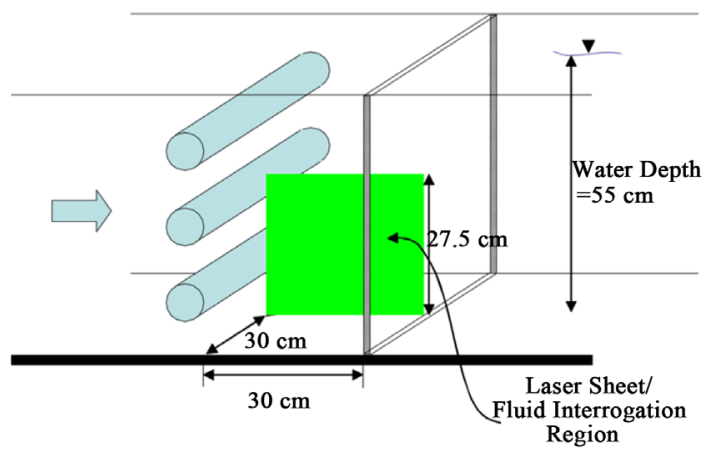

(b)

Figure 9. Flume and test section configuration (a) and PIV Interrogation Windows (b). From [99], reproduced with permission from the Journal of Experimental Biology.

1024 pixels. A synchronizer was used to control the CCD camera and the timing of the laser pulses. A schematic of the experimental setup is shown in Figure 10(a). This laboratory tests demonstrated the applicability of PIV to characterize flows around fish. The measurements also disclosed unsteady vortex shedding generated in the wake behind the fish, and very high vorticity and high stress areas around the fish head. The area with the highest stress is just down-stream the fish head. Figure 10(b) is an example of mean velocity vectors.

Liao et al. (2003) [102] studied experimentally the effect of vortices on the locomotion of fish. A DPIV system was applied [103] in a water tank where a D-section cylinder was placed to generate vortices as shown in Figure 11. The DPIV system, used to measure the flow field, consisted of two high-speed video cameras (NAC HSV-500) and an argon-ion laser with a laser sheet thickness of $1-2 \mathrm{~mm}$. Silver-coated glass spheres with a mean $d_{p}=12 \mathrm{~mm}$ were used as seeding particles. The purpose was to find the interaction between fish and vortices generated behind the D-section cylinder see Figure 12(a) where arrows represent the direction and magnitude of flow (The scale arrow denotes $0.56 \mathrm{~m} / \mathrm{s}$ ). Red corresponds to vorticity (rad/s) for clockwise direction and blue corresponds to vorticity for counterclockwise direction. Figure 12(b) represents midlines for seven consecutive tail-beats. Standard errors in vortex position are given as bar lengths within each vortex. In Figure 12(c) the phase between body and vortices, where $180^{\circ}$ represents slaloming in between vortices and $0^{\circ}$ or $360^{\circ}$ represents vortex interception. Checkered circles represent the center of mass of fish. Bars in light gray represent standard error.

The main result of this PIV study is that fish uses environmental flow vortices to conserve energy and maintain position in the stream during upstream migration.

Siddiqui (2007) [104] employed a two-component PIV technique to obtain velocity fields around a freely swimming fish. The experiments were carried out in a $0.30 \mathrm{~m}$ long tank made of glass having width and height of $0.12 \mathrm{~m}$ and $0.20 \mathrm{~m}$ respectively as shown in Figure 13. The PIV set-up consists of a Nd:YAG laser having an energy of $25 \mathrm{~mJ}$ to illuminate the flow area, a CCD camera with a resolution of $1600 \times 1200$ pixels, a pulse generator, some laser optics lenses, mirrors etc. for transmitting light and a computer with frame grabber facility. AVideoSavant software was used to evaluate the snap-shots.

Hollow glass spheres with mean $d_{p}=10 \mu \mathrm{m}$ were used to seed the fluid. A constant water height of $0.18 \mathrm{~m}$ was maintained and the tank was divided into different areas with a Plexiglas sheet so that a $65 \mathrm{~mm}$ long goldfish could swim freely in a $0.30 \mathrm{~m}$ long and $0.08 \mathrm{~m}$ wide section. Images of swimming fish were captured from a $100 \times 74 \mathrm{~mm}^{2}$ observation window for a duration time of 5 minutes and images were captured at a frequency of $30 \mathrm{~Hz}$. Finally the images were analyzed to find the velocity fields see Figure 14. The PIV measurements disclosed that jets are created by the fins and tails of the fish and vortices are seen in the wake behind the fish.

Sakakibara et al. (2004) [105] performed an experimental study on swimming fish. This was done in a plexiglas tank having a length of $1.0 \mathrm{~m}$, a width of $0.20 \mathrm{~m}$ and a water depth of $0.30 \mathrm{~m}$. A gold fish with a length of $0.11 \mathrm{~m}$ was allowed to swim freely within this tank. The authors did not use any external control for the motion 


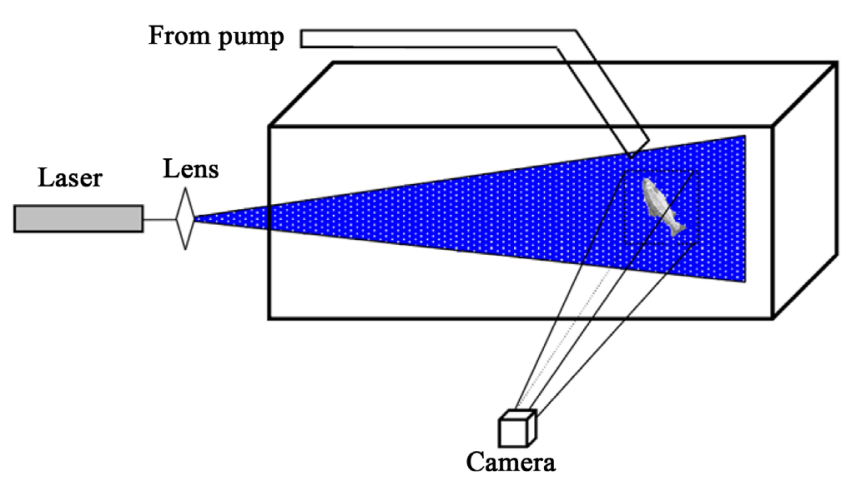

(a)

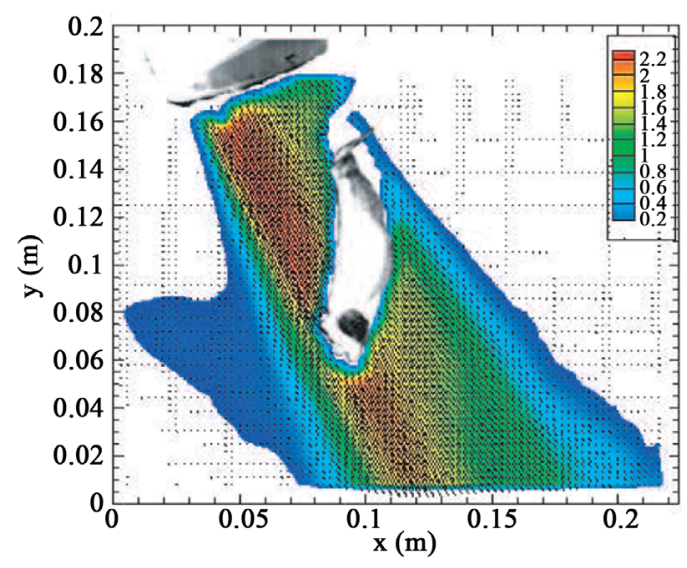

(b)

Figure 10. PIV measurements of a laboratory fish way (a) PIV set-up; (b) Example of mean velocity vectors. From [100], reproduced with permission from Dr. Marshall C. Richmond.

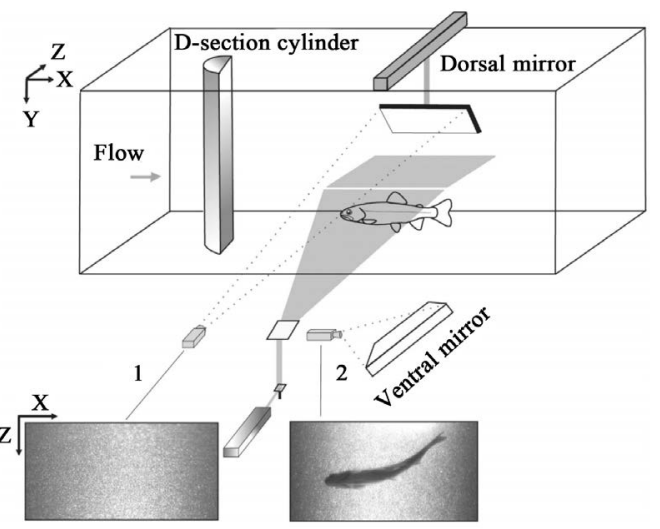

Figure 11. DPIV experimental setup. From [102], reproduced with permission from the American Association for the Advancement of Science.
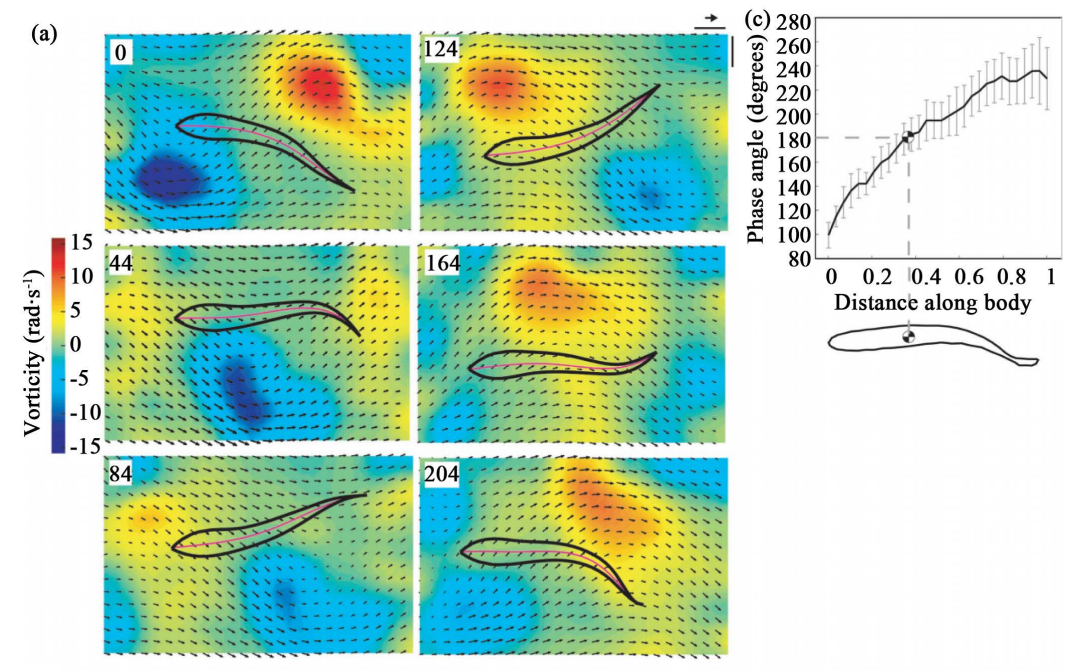

(b)

Figure 12. Interaction of fish with cylinder vortices. From [102], reproduced with permission from the American Association for the Advancement of Science. 


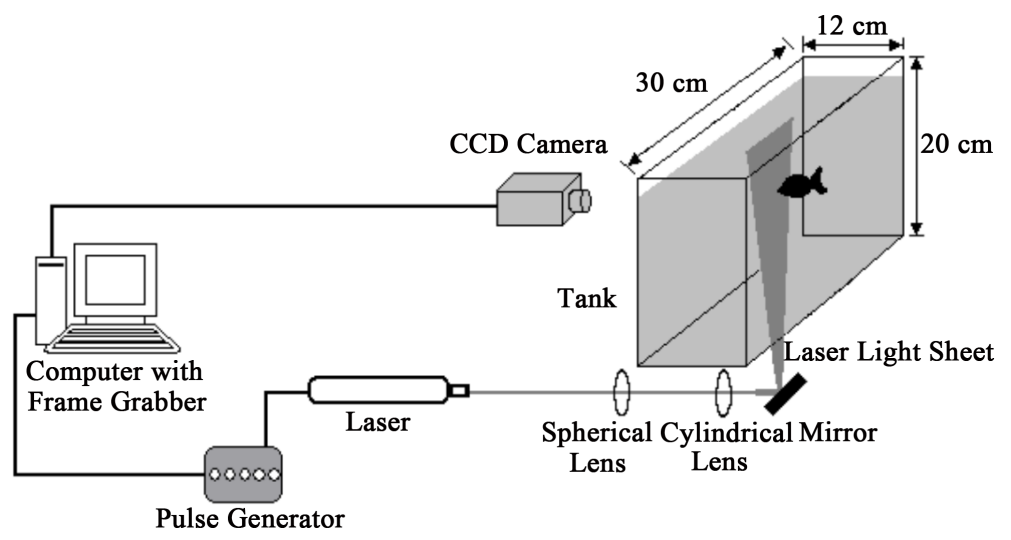

Figure 13. Schematic of the PIV experimental setup. From [104], reproduced with permission from the Journal of Measurement Science and Technology.

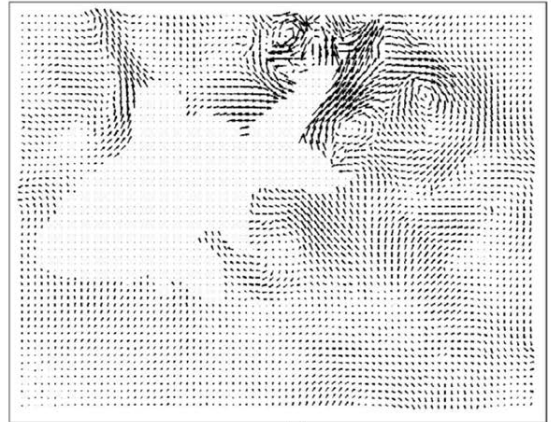

(a)

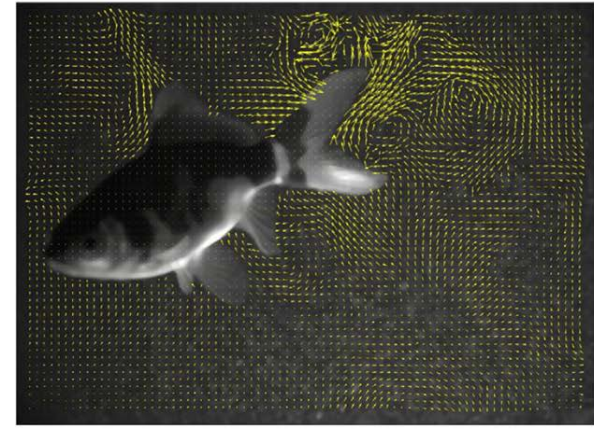

(b)

Figure 14. The velocity fields (a) obtained from the preprocessed PIV image pair; (b) superimposed on the PIV image. From [104], reproduced with permission from the Journal of Measurement Science and Technology.

of fish but waited until the fish entered the region of view and took turning motions. Stereoscopic PIV was used to measure the three component velocity distribution around the fish. An Nd-YAG laser equipped with an in-house laser delivery arm produced a 2 mm-thick laser light sheet to illuminate the flow field. A total of four CCD cameras were employed at four different locations for stereoscopic PIV measurement, two for the stereoscopic PIV and two to capture the fish. The complete experimental facility is shown in Figure 15. In the PIV results shown in Figure 16, the authors found different fish turning-motion processes at different times such as the fish took up a curved shape, its body became C-shape at the starting of the turning motion; the body started to resume a straight shape by transmitting the bending point toward the back, and formed a "side jet" in the center of counter-rotating vortices, that provided angular momentum to the fish body and surrounding added mass; finally, the thrust jet was released toward the back and the fish body moved forward.

\section{Discussion}

PIV can be used to gather instantaneous flow field information and can considerably reduce the time for experiments as compared to Laser Doppler Anemometry, for instance. It is here shown that PIV can be a versatile tool for biological or ecological studies such as fish migration as it visualizes the fluid area when it makes contact with a surface or object [106]. Regarding fish migration the PIV measurement may be divided into pure studies of the motion of fish and flow fields connected to fish migration. Velocity and turbulent quantities within or in the vicinity of fishways is of interest as well as flow around fish and fish turning movement. Additionally, PIV has been successfully applied on studying fish swimming speed and stability where PIV results find some influences of turbulence. PIV has been employed to measure vorticities and other unsteady quantities of the flow in a fishway where vorticity, turbulent kinetic energy (TKE) and velocity fields were effectively measured. PIV 


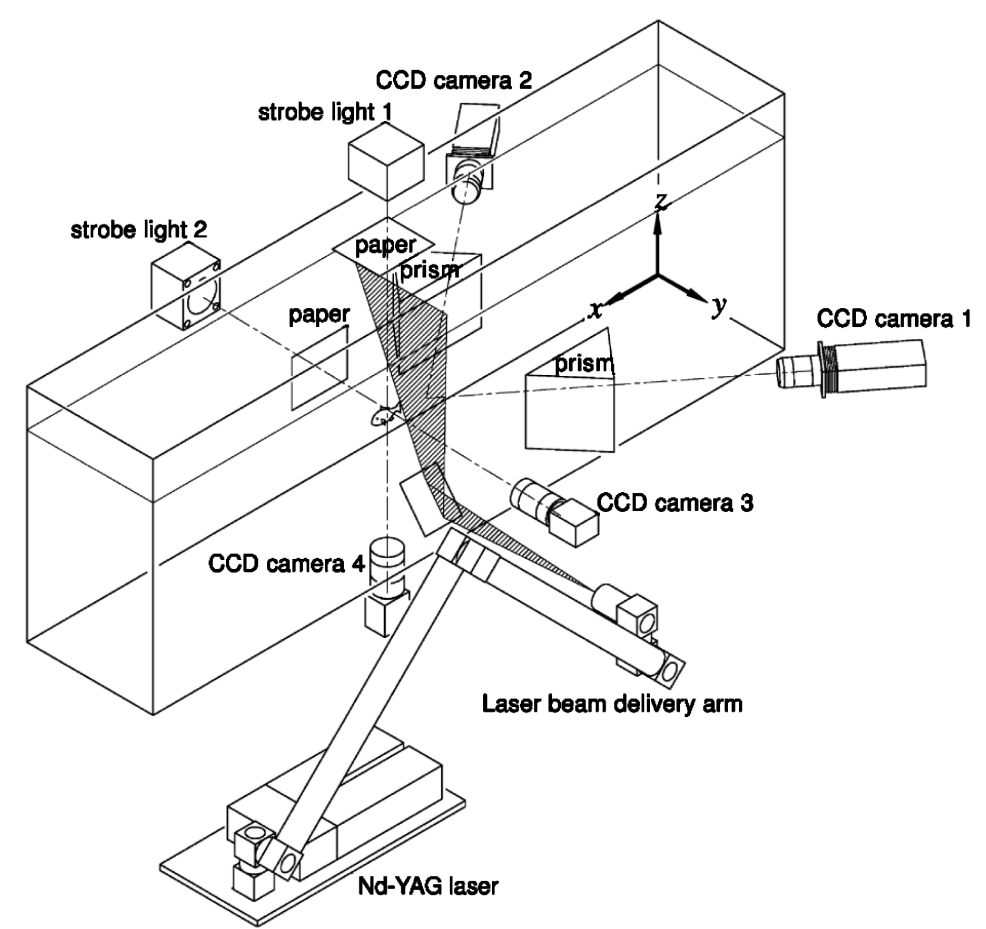

Figure 15. Experimental arrangements. From [105], reproduced with permission from the Springer.

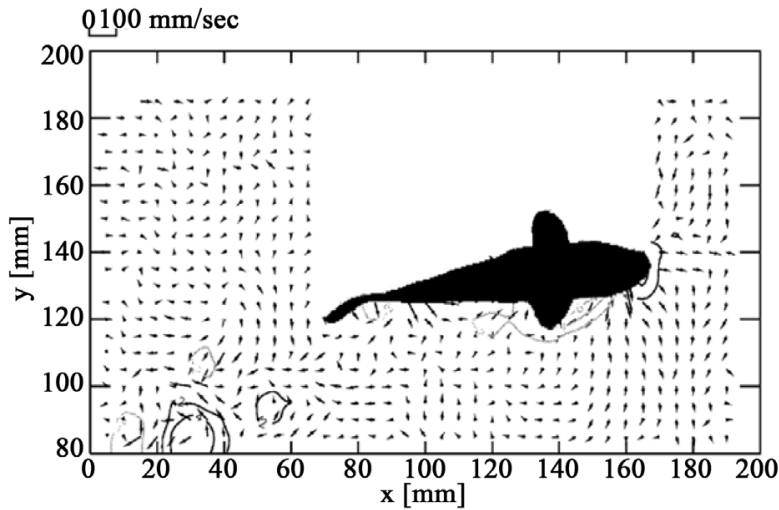

(a)

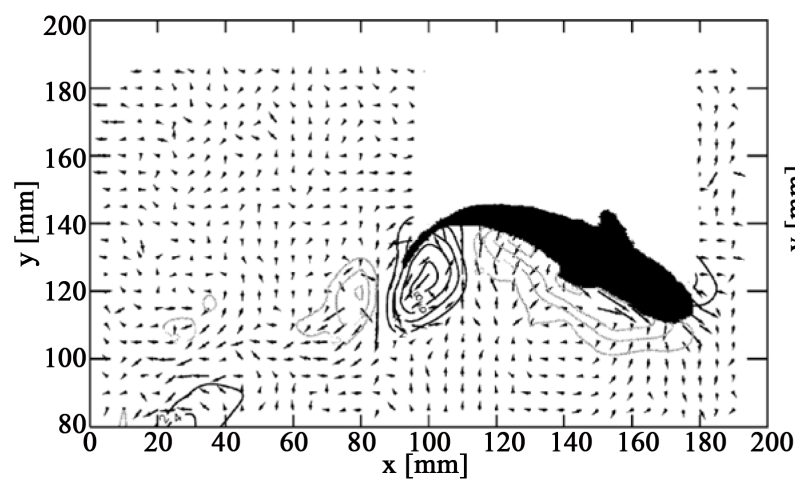

(c)

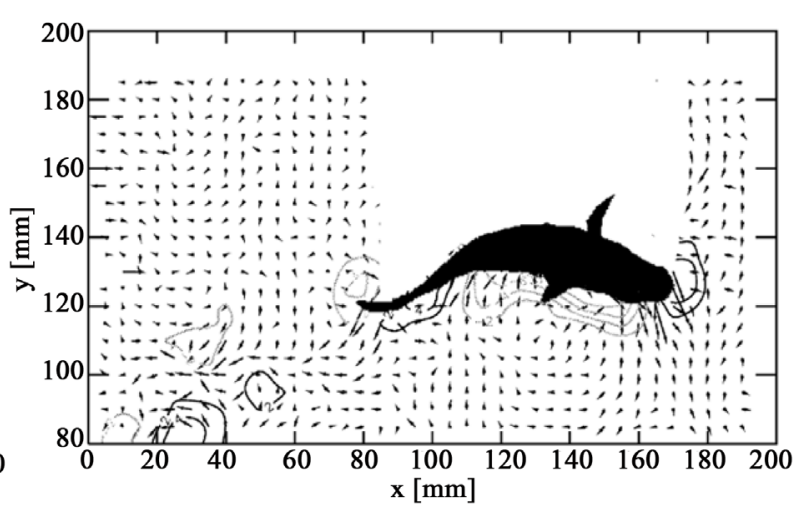

(b)

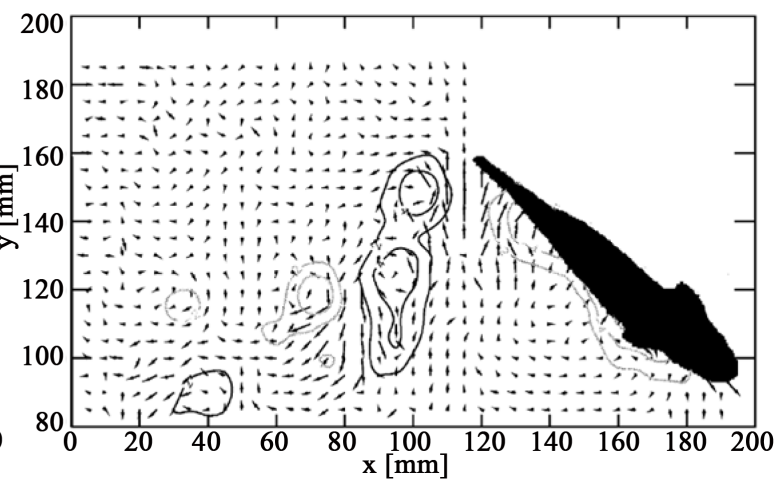

(d)

Figure 16. Velocity vectors around a turning fish as measured with stereoscopic PIV: (a) $t=0 \mathrm{~s}$; (b) $t=1 / 15 \mathrm{~s}$; (c) $\mathrm{t}=3 / 15 \mathrm{~s}$; (d) $t=8 / 15$ s. From [105], reproduced with permission from the Springer. 
has also been used to validate some numerical analysis [25] [107]-[115] of fishways, for example, Khodier, M.A et al. (2012) [44] validated their numerical studies with PIV experimental studies. Apart from this, Stereoscopic PIV and Tomographic PIV are able to get the three-component (3-D) velocity information in the planar region illuminated by a laser sheet. These types of 3D-PIV systems are already in use on studying fish migration, for instance, Sakakibara et al. (2004) [105] used Stereoscopic PIV on studying swimming movement of a live fish and Mendelson, L. et al. (2015) [116] used 3D synthetic aperture PIV to analyze wake of a freely swimming fish. Moreover, Scarano (2013) [71] has reviewed application of Tomographic PIV in various experimental studies and he found that the use of this type of Tomo-PIV is rapidly increasing for experimental measurements.

However, as every measuring technique has some errors, PIV is not free from errors regardless of velocity range measured [117]. Compared with other experimental techniques, PIV is a measuring technique where accuracy is straightforwardly determined by the error in displacement and the time delay uncertainty between pulses. Similarly, the error in displacement is a prior uncertainty source for all sorts of PIV applications and difficult to compute, as measuring PIV itself may be found as a series of error generating steps [78]. In additions the filtering often applied in a post-processing of the data may introduce additional errors.

Initially, it is assumed that the seeding or tracer particles follow the turbulent flow. This is however due their size, shape, mass and density and compared to the characteristics of the fluid and the flow. The ability for a particle to follow the flow is often described with the Stokes number, which in its simplest form may be written as:

$$
S_{t k}=\frac{t_{0} u_{0}}{l_{0}}
$$

where $t_{0}$ is the relaxation time of the particles, $u_{0}$ is a velocity, $l_{0}$ is a characteristic dimension typically the diameter of the particles.

Other errors are found when the image acquisition and analysis procedure are in progress. The quality of particle image, size of interrogation area and the statistical correlating procedure are dependent on the accuracy of the experimentally measured velocity data [77] [117]-[119]. Additionally, the skills and experiences working on PIV of the researcher are also related to the accuracy of measurement. Ullum et al. [119] studied time-averaged PIV data for a single point in a grid-generated turbulence to find the effect of sample size on measuring accuracy in its early decay. It was observed that 100 vector maps for a component of average or mean velocity were needed for uncertainties of averages at a specified point to be within $1 \%$ for a flow of $10 \%$ turbulence intensity. Nevertheless, 20000 vector maps were required for a component of normal stress with this level of accuracy. This study showed the requirement for larger sample sizes for higher order statistics. Also, inadequate laser intensity, stiffness of the optical light sheet and poor-spatial resolution of the CCD camera may be a problem. Since these significant drawbacks restrict the uses of PIV system in several cases, then it is essential to develop required optical arrangement and technology for camera shooting to overcome these drawbacks. However, a PIV system is quite expensive, large, and difficult to use for experimental measurements. Perfect PIV measurement of fish ways requires a comparatively large amount of investment in equipment, time and experimental skill and experience, especially for cases when the flow around fish is in focus.

\section{Conclusion}

The major technologies of an ideal PIV system for measuring fluid dynamics phenomena in fish migration related equipments were reviewed. There was no universally applicable PIV system found for every case of experimental measurement. Many compromises and decisions have to be carefully taken for various practical applications. The researchers should take important consideration during selection of suitable PIV system parameters according to their particular requirements. The reviewed publications indicated that PIV has progressively converted into the most popular and resourceful experimental instrument to measure fluid dynamics phenomena in the fish migration process. PIV has been able to overcome the drawback of the conventional point based velocity measuring techniques and become a high-tech, non-intrusive, entire flow field measuring technique, and presenting instantaneous velocity information in an entire plane. The Tomo-PIV (3D-PIV) is now capable to measure all three components instantaneous velocity, having real-time three-component flow structures for interested areas, for instance, around a fish body. However, PIV is sometimes not the optimum instrument for some very complex flow measurements as some commercially available PIV is frequently restricted to the obstruction of optical paths and the limit of image size. Thus, it is essentially to develop large or full scale optical technology as well as technology of capturing images to overcome the drawbacks. 


\section{Acknowledgements}

This work has been funded by the collaboration initiative StandUp for Energy. The research program is a part of the Swedish government's commitment to high quality research in areas of strategic importance.

\section{References}

[1] Mallen-Cooper, M. (2000) Taking the Mystery out of Migration. In: Smith, D.A. and Koen, J.D., Eds., Fish movement and Migration, Australian Society for Fish Biology Workshop Proceedings, Hancock Bendigo, 101-111.

[2] Aro, E. (1989) A Review of Fish Migration Patterns in the Baltic. Rapports et Procès-Verbaux des Réunions du Conseil International pour l'Exploration de la Mer, 190, 72-96.

[3] Buchanan, R.R. (1981) Integrated Fish Migration System. Google Patents.

[4] Jonsson, N. (1991) Influence of Water Flow, Water Temperature and Light on Fish Migration in Rivers. Nordic Journal of Freshwater Research, 66, 20-35 http://scholarworks.umass.edu/fishpassage_journal_articles/1327/

[5] Schönfisch, B. and Kinder, M. (2002) A Fish Migration Model. In: Cellular Automata, Springer, Volume 2493 of the series, Lecture Notes in Computer Science, 210-219. http://dx.doi.org/10.1007/3-540-45830-1 20

[6] Jones, F.H. (1968) Fish Migration. Hodder Arnold, London.

[7] Harden Jones, F.R. (1968) Fish Migration. http://library.wur.nl/WebQuery/clc/360596

[8] Larinier, M. (2000) Dams and Fish Migration. World Commission on Dams, FAO Fisheries Technical Paper, 26. http://cybrary.friendsofmerrymeetingbay.org/pages/20000630_Dams.org_DamsandFishMigration.pdf

[9] Ueda, H. and Yamauchi, K. (1995) Biochemistry of Fish Migration. Biochemistry and Molecular Biology of Fishes, 5, 265-279. http://dx.doi.org/10.1016/S1873-0140(06)80040-8

[10] Katopodis, C. (1992) Introduction to Fishway Design. Freshwater Institute, Central and Arctic Region, Department of Fisheries and Oceans, Freshwater Institute Central and Arctic Region Department of Fisheries and Oceans 501 University Crescent Winnipeg, Manitoba Canada, R3T 2N6. http://www.wra.gov.tw/public/attachment/41110254871.pdf

[11] Buck, S. (2013) Determining the Best Location for a Nature-Like Fishway in Gavle River, Sweden. http://www.diva-portal.org/smash/record.jsf?pid=diva2\%3A663787\&dswid=-7015

[12] Evans, W.A. and Johnston, F.B. (1980) Fish Migration and Fish Passage: A Practical Guide to Solving Fish Passage Problems. Forest Service, Engineering Staff.

[13] Larinier, M. (2001) Environmental Issues, Dams and Fish Migration. FAO Fisheries Technical Paper, 419, 45-89.

[14] Jungwirth, M., Schmutz, S. and Weiss, S. (1998) Fish Migration and Fish Bypasses. Vol. 4, Fishing News Books, Oxford.

[15] Dingle, H. (2014) Migration: The Biology of Life on the Move. Oxford University Press, Oxford. http://dx.doi.org/10.1093/acprof:oso/9780199640386.001.0001

[16] Claiborne, A.M., et al. (2014) Evidence for Selective Mortality in Marine Environments: The Role of Fish Migration Size, Timing, and Production Type.

[17] Migration, F. (2015) Fish Migration, Living North Sea. http://www.living-north-sea.eu/fish-migration/

[18] Amos, A.L. (2014) Dam Removal and Hydropower Production in the United States-Ushering in a New Era. Journal of Environmental Law and Litigation, 29, 1-443. https://scholarsbank.uoregon.edu/xmlui/handle/1794/17841

[19] Shi, X., et al. (2015) Development of Fish Passage in China. Fisheries, 40, 161-169. http://dx.doi.org/10.1080/03632415.2015.1017634

[20] Dewals, B., et al. (2015) Erosion and Sedimentation Issues in a Hydropower Project: Assessing Impacts and Opportunities. 45th International Symposium on Hydraulic Engineering Aachen (IWASA), Aachen, 8-9 January 2015.

[21] Kirk, M., Caudill, C.C. and Keefer, M.L. (2014) Evaluating Pacific Lamprey Behavior in Fishways at Bonneville and John Day Dams Using Dual-Frequency Identification Sonar (DIDSON), 2013. Department of Fish and Wildlife Sciences, University of Idaho, Moscow, Idaho.

[22] Utrup, N. (2014) Fish Passage at Hydropower Dams in Wisconsin and Concerns with Invasive Species, Disease, and Contaminants. International Conference on Engineering and Ecohydrology for Fish Passage, Madison, 9-11 June 2014. http://scholarworks.umass.edu/cgi/viewcontent.cgi?article=1621\&context=fishpassage_conference

[23] Keefer, M.L., Caudill, C.C. and Moser, M.L. (2014) Fishway Bottleneck Relief Models: A Case Study Using Radio-Tagged Pacific Lampreys. Transactions of the American Fisheries Society, 143, 1049-1060.

[24] Hahn, L. (2014) Fishway Use and Movements of Giant Migratory Catfishes Downstream of a Large Hydropower Dam 
in the Brazilian Amazon. International Conference on Engineering and Ecohydrology for Fish Passage, Madison, 9-11 June 2014. http://scholarworks.umass.edu/fishpassage_conference/2014/June9/77/

[25] Bombač, M., et al. (2014) Numerical and Physical Model Study of a Vertical Slot Fishway. Journal of Hydrology and Hydromechanics, 62, 150-159. http://dx.doi.org/10.2478/johh-2014-0013

[26] Redeker, M. (2014) An Overview of the New German Fishway Standard for Upstream Fish Passage. International Conference on Engineering and Ecohydrology for Fish Passage, Madison, 9-11 June 2014. http://scholarworks.umass.edu/cgi/viewcontent.cgi?article=1545\&context=fishpassage_conference

[27] Hogan, T.W., Cada, G.F. and Amaral, S.V. (2014) The Status of Environmentally Enhanced Hydropower Turbines. Fisheries, 39, 164-172. http://dx.doi.org/10.1080/03632415.2014.897195

[28] Rajaratnam, N., Katopodis, C. and Paccagnan, R. (1992) Field Studies of Fishways in Alberta. Canadian Journal of Civil Engineering, 19, 627-638. http://dx.doi.org/10.1139/192-072

[29] Baumgartner, L., Zampatti, B., Jones, M., Stuart, I. and Mallen-Cooper, M. (2014) Fish Passage in the Murray-Darling Basin, Australia: Not Just an Upstream Battle. Ecological Management \& Restoration, 15, 28-39. http://dx.doi.org/10.1111/emr.12093

[30] Clay, C.H. (1994) Design of Fishways and Other Fish Facilities. CRC Press, Boca Raton.

[31] Thorncraft, G. and Harris, J.H. (2000) Fish Passage and Fishways in New South Wales-A Status Report. Cooperative Research Centre for Freshwater Ecology Canberra, Australia.

[32] Rajaratnam, N., Van der Vinne, G. and Katopodis, C. (1986) Hydraulics of Vertical Slot Fishways. Journal of Hydraulic Engineering, 112, 909-927. http://dx.doi.org/10.1061/(ASCE)0733-9429(1986)112:10(909)

[33] Rajaratnam, N., Katopodis, C. and Solanki, S. (1992) New Designs for Vertical Slot Fishways. Canadian Journal of Civil Engineering, 19, 402-414. http://dx.doi.org/10.1139/192-049

[34] Katopodis, C. and Williams, J.G. (2012) The Development of Fish Passage Research in a Historical Context. Ecological Engineering, 48, 8-18. http://dx.doi.org/10.1016/j.ecoleng.2011.07.004

[35] Mallen-Cooper, M.G. (1996) Fishways and Freshwater Fish Migration on South-Eastern Australia. Thesis, University of Technology Sydney, Sydney. https://opus.lib.uts.edu.au/handle/2100/548

[36] Hamano, T., Yoshimi, K., Hayashi, K.-I. and Shokita, S. (1995) Experiments on Fishways for Freshwater Amphidromous Shrimps. Nippon Suisan Gakkaishi, 61, 171-178. http://scholarworks.umass.edu/fishpassage_journal_articles/1299/

[37] Laine, A., Kamula, R. and Hooli, J. (1998) Fish and Lamprey Passage in a Combined Denil and Vertical Slot Fishway. Fisheries Management and Ecology, 5, 31-44. http://dx.doi.org/10.1046/j.1365-2400.1998.00077.x

[38] Jia, J.S. (2002) Fishways: Biological Basis, Design Criteria and Monitoring. http://scholarworks.umass.edu/fishpassage_journal_articles/1889/

[39] Lindmark, E. (2008) Flow Design for Migrating Fish. Doctoral Thesis, Luleå University of Technology, Luleå. http://pure.ltu.se/portal/en/publications/flow-design-for-migrating-fish(aa9883e0-b168-11dd-9c9d-000ea68e967b).html

[40] Kamula, R. (2001) Flow over Weirs with Application to Fish Passage Facilities. University of Oulu, Oulu.

[41] Silva, A.T., et al. (2015) Behaviour and Locomotor Activity of a Migratory Catostomid during Fishway Passage. PLoS ONE, 10, e0123051.

[42] Guo, H.Y., Qiu, W.J., Wu, Z.Q. and Xie, L.Q. (2015) Experimental Verification of a New Ecological Fishway. In: Xie, L.Q., Ed., Advanced Engineering and Technology II, CRC Press, Boca Raton, 103-109. http://dx.doi.org/10.1201/b18180-18

[43] Boiten, W. (2002) Flow Measurement Structures. Flow Measurement and Instrumentation, 13, 203-207. http://dx.doi.org/10.1016/S0955-5986(02)00057-2

[44] Khodier, M. and Tullis, B.P. (2012) Using Particle Image Velocimetry (PIV) System in Fish Passage through Rehabilitated Culverts. In: Tullis, B. and Janssen, R., Eds., 4th International Junior Researcher and Engineer Workshop on Hydraulic Structures, IJREWHS’12, Utah State University, Logan.

[45] Schilt, C.R. (2007) Developing Fish Passage and Protection at Hydropower Dams. Applied Animal Behaviour Science, 104, 295-325. http://dx.doi.org/10.1016/j.applanim.2006.09.004

[46] Michigan Department of Natural Resources. Cited 1 May 2015.

[47] Lövgren, L. (2015) The Dams Debate in Sweden. Cited 21 January 2015.

[48] STandUP for Energy (2015) Bruksfors Hydro Power Plant—Development of Small Scale Environmental Hydro Power. Cited 10 September 2015. http://www.standupforenergy.se/aktuellt/bruksfors-hydro-power-station/

[49] Michigan Department of Natural Resources (2015) What Is a Fish Ladder and Weir? Cited 15 June 2015. http://www.michigan.gov/dnr/0,4570,7-153-10364 52259 19092-46291--,00.html 
[50] Willert, C.E. and Gharib, M. (1991) Digital Particle Image Velocimetry. Experiments in Fluids, 10, 181-193. http://dx.doi.org/10.1007/BF00190388

[51] Adrian, R.J. and Westerweel, J. (2011) Particle Image Velocimetry. Vol. 30, Cambridge University Press, Cambridge.

[52] Lourenco, L. (1994) Particle Image Velocimetry.

[53] Lourenco, L., Krothapalli, A. and Smith, C. (1989) Particle Image Velocimetry. In: Gad-el-Hak, M., Ed., Advances in Fluid Mechanics Measurements, Springer, Berlin, 127-199. http://dx.doi.org/10.1007/978-3-642-83787-6_4

[54] Prasad, A.K. (2000) Particle Image Velocimetry. Current Science-Bangalore, 79, 51-60.

[55] Grant, I. (2014) Particle Image Velocimetry: A Review. Proceedings of the Institution of Mechanical Engineers, Part C: Journal of Mechanical Engineering Science.

[56] Adrian, R.J. (2005) Twenty Years of Particle Image Velocimetry. Experiments in Fluids, 39, 159-169. http://dx.doi.org/10.1007/s00348-005-0991-7

[57] Chung, H., et al. (2011) Flow Characteristics by Particle Image Velocimetry in Liquefied Natural Gas Vaporizer Model with Several Baffles. Journal of Central South University of Technology, 18, 1719-1725. http://dx.doi.org/10.1007/s11771-011-0893-1

[58] Sayeed-Bin-Asad, S.M., et al. (2011) PIV Measurement of the Shell Side Flow Characteristics of Shell-and-Tube LNG Vaporizer. 4th International Conference GeoProc2011: Cross Boundaries through THMC Integration, Perth, 6-9 July 2011. http://www.uwa.edu.au/_data/assets/pdf_file/0005/1701626/GeoProc2011_Conference_Program.pdf

[59] Grant, I. (1997) Particle Image Velocimetry: A Review. Proceedings of the Institution of Mechanical Engineers, Part C: Journal of Mechanical Engineering Science, 211, 55-76. http://dx.doi.org/10.1243/0954406971521665

[60] Stanislas, M., Okamoto, K. and Kähler, C. (2003) Main Results of the First International PIV Challenge. Measurement Science and Technology, 14, R63-R89. http://dx.doi.org/10.1088/0957-0233/14/10/201

[61] Stanislas, M., et al. (2005) Main Results of the Second International PIV Challenge. Experiments in Fluids, 39, 170191. http://dx.doi.org/10.1007/s00348-005-0951-2

[62] Stanislas, M., et al. (2008) Main Results of the Third International PIV Challenge. Experiments in Fluids, 45, 27-71. http://dx.doi.org/10.1007/s00348-008-0462-z

[63] Dabiri, D. (2009) Digital Particle Image Thermometry/Velocimetry: A Review. Experiments in Fluids, 46, $191-241$. http://dx.doi.org/10.1007/s00348-008-0590-5

[64] Green, T. (2009) Particle Image Velocimetry in Practice. Luleå Tekniska Universitet, Luleå.

[65] Raffel, M., et al. (2007) Particle Image Velocimetry: A Practical Guide. Springer, Berlin.

[66] Green, T. (2011) PIV in practice, in Division of Fluid- and Experimental Mechanics. Luleå University of Technology, Luleå.

[67] PIV (2015) Planned Experiments with 2-D Particle Image Velocimetry Analysis (PIV) and Some Examples of Results. Cited 21 April 2015.

[68] Todde, V., Spazzini, P.G. and Sandberg, M. (2009) Experimental Analysis of Low-Reynolds Number Free Jets. Experiments in Fluids, 47, 279-294. http://dx.doi.org/10.1007/s00348-009-0655-0

[69] Larsson, I.S., Johansson, S.P.A., Lundström, T.S. and Marjavaara, B.D. (2015) PIV/PLIF Experiments of Jet Mixing in a Model of a Rotary Kiln. Experiments in Fluids, 56, 111. http://dx.doi.org/10.1007/s00348-015-1984-9

[70] Larsson, I.S., et al. (2012) PIV Analysis of Merging Flow in a Simplified Model of a Rotary Kiln. Experiments in Fluids, 53, 545-560. http://dx.doi.org/10.1007/s00348-012-1309-1

[71] Scarano, F. (2013) Tomographic PIV: Principles and Practice. Measurement Science and Technology, 24, Article ID: 012001. http://dx.doi.org/10.1088/0957-0233/24/1/012001

[72] Khodier, M.A. (2014) Weir-Baffled Culvert Hydrodynamics Evaluation for Fish Passage Using Particle Image Velocimetry and Computational Fluid Dynamic Techniques. Civil and Environmental Engineering, Utah State University. http://digitalcommons.usu.edu/etd/3078/

[73] Park, J., Im, S., Sung, H.J. and Park, J.S. (2015) PIV Measurements of Flow around an Arbitrarily Moving Free Surface. Experiments in Fluids, 56, 56. http://dx.doi.org/10.1007/s00348-015-1920-z

[74] Briggs, A.A., Fleming, A., Ojeda, R. and Binns, J.R. (2014) Tracking the Vortex Core From a Surface-Piercing Foil by Particle Image Velocimetry (PIV) Using Fluorescing Particles. 19th Australasian Fluid Mechanics Conference, Melbourne. http://people.eng.unimelb.edu.au/imarusic/proceedings/19/196.pdf

[75] Saber, A. (2014) Transport of Particles in Turbulent Flow with Application to Bio-Fuels. Luleå Tekniska Universitet, Luleå.

http://swepub.kb.se/bib/swepub:oai:pure.atira.dk:publications/7990f6a9-c7fb-4bab-a530-5cf6d1000050?tab2=abs\&lan guage $=\mathrm{en}$ 
[76] Tarrade, L., et al. (2011) Detailed Experimental Study of Hydrodynamic Turbulent Flows Generated in Vertical Slot Fishways. Environmental Fluid Mechanics, 11, 1-21. http://dx.doi.org/10.1007/s10652-010-9198-4

[77] Hart, D.P. (2000) PIV Error Correction. Experiments in Fluids, 29, 13-22. http://dx.doi.org/10.1007/s003480050421

[78] Cao, X., Liu, J.J., Jiang, N. and Chen, Q.Y. (2014) Particle Image Velocimetry Measurement of Indoor Airflow field: A Review of the Technologies and Applications. Energy and Buildings, 69, 367-380. http://dx.doi.org/10.1016/j.enbuild.2013.11.012

[79] Abdelsalam, D., Stanislas, M. and Coudert, S. (2014) PIV Camera Response to High Frequency Signal: Comparison of CCD and CMOS Cameras Using Particle Image Simulation. Measurement Science and Technology, 25, Article ID: 084007. http://dx.doi.org/10.1088/0957-0233/25/8/084007

[80] LaVision (2015) CCD and sCMOS Cameras. Cited 2 May 2015.

[81] Hain, R., Kähler, C.J. and Tropea, C. (2007) Comparison of CCD, CMOS and Intensified Cameras. Experiments in Fluids, 42, 403-411. http://dx.doi.org/10.1007/s00348-006-0247-1

[82] Boyle, W.S. and Smith, G.E. (1970) Charge Coupled Semiconductor Devices. Bell System Technical Journal, 49, 587593. http://dx.doi.org/10.1002/j.1538-7305.1970.tb01790.x

[83] Dantec Dynamics, F.E.C.S. (2015). www.dantecdynamics.com

[84] Melling, A. (1997) Tracer Particles and Seeding for Particle Image Velocimetry. Measurement Science and Technology, 8, 1406-1416. http://dx.doi.org/10.1088/0957-0233/8/12/005

[85] Bosbach, J., Kühn, M. and Wagner, C. (2009) Large Scale Particle Image Velocimetry with Helium Filled Soap Bubbles. Experiments in Fluids, 46, 539-547. http://dx.doi.org/10.1007/s00348-008-0579-0

[86] Willert, C.E., Wereley, S.T. and Kompenhans, J. (2007) Particle Image Velocimetry: A Practical Guide. Springer, Berlin.

[87] Zhang, T., Celik, D. and Van Sciver, S. (2004) Tracer Particles for Application to PIV Studies of Liquid Helium. Journal of Low Temperature Physics, 134, 985-1000. http://dx.doi.org/10.1023/B:JOLT.0000013213.61721.51

[88] Dantec Dynamics, Dynamic Studio Manual, Private Communication.

[89] Theunissen, R., Scarano, F. and Riethmuller, M.L. (2010) Spatially Adaptive PIV Interrogation Based on Data Ensemble. Experiments in Fluids, 48, 875-887. http://dx.doi.org/10.1007/s00348-009-0782-7

[90] Westerweel, J. and Scarano, F. (2005) Universal Outlier Detection for PIV Data. Experiments in Fluids, 39, $1096-1100$. http://dx.doi.org/10.1007/s00348-005-0016-6

[91] Kitzhofer, J., Ergin, F. and Jaunet, V. (2012) 2D Least Squares Matching Applied to PIV Challenge Data (Part 1). 16th International Symposium on Applications of Laser Techniques to Fluid Mechanics, July 2012.

[92] Brücker, C., Hess, D. and Kitzhofer, J. (2013) Single-View Volumetric PIV via High-Resolution Scanning, Isotropic Voxel Restructuring and 3D Least-Squares Matching (3D-LSM). Measurement Science and Technology, 24, Article ID: 024001. http://dx.doi.org/10.1088/0957-0233/24/2/024001

[93] Kitzhofer, J., Nonn, T. and Brücker, C. (2011) Generation and Visualization of Volumetric PIV Data Fields. Experiments in Fluids, 51, 1471-1492. http://dx.doi.org/10.1007/s00348-011-1176-1

[94] Bohm, L.L., Enderle, H.F. and Fleifßner, M. (1992) High-Density Polyethylene Pipe Resins. Advanced Materials, 4, 234-238. http://dx.doi.org/10.1002/adma.19920040317

[95] Green, T., et al. (2011) Flow Characterization of an Attraction Channel as Entrance to Fishways. River Research and Applications, 27, 1290-1297. http://dx.doi.org/10.1002/rra.1426

[96] LaVision (2014) DaVis, Version 8.1, LaVision GmbH, Göttingen, Germany.

[97] Düwel, I., et al. (2004) Laser-Induced Fluorescence of Tracers Dissolved in Evaporating Droplets. Applied Physics B, 78, 127-131. http://dx.doi.org/10.1007/s00340-003-1378-1

[98] Traverse (2015) 3-Axis Long Traverse System-T3DL. Cited 31 May 2015.

[99] Tritico, H. and Cotel, A. (2010) The Effects of Turbulent Eddies on the Stability and Critical Swimming Speed of Creek Chub (Semotilus atromaculatus). The Journal of Experimental Biology, 213, 2284-2293. http://dx.doi.org/10.1242/jeb.041806

[100] Deng, Z., et al. (2004) Study of Fish Response Using Particle Image Velocimetry and High-Speed, High-Resolution Imaging. Pacific Northwest National Laboratory (PNNL), Richland, WA (US). http://dx.doi.org/10.2172/1218166

[101] Konow, N. and Roberts, T.J. (2015) The Series Elastic Shock Absorber: Tendon Elasticity Modulates Energy Dissipation by Muscle during Burst Deceleration. Proceedings of the Royal Society of London B: Biological Sciences, 282, Article ID: 20142800.

[102] Liao, J.C., Beal, D.N., Lauder, G.V. and Triantafyllou, M.S. (2003) Fish Exploiting Vortices Decrease Muscle Activity. Science, 302, 1566-1569. http://dx.doi.org/10.1126/science.1088295 
[103] Drucker, E.G. and Lauder, G.V. (1999) Locomotor Forces on a Swimming Fish: Three-Dimensional Vortex Wake Dynamics Quantified Using Digital Particle Image Velocimetry. Journal of Experimental Biology, 202, 2393-2412.

[104] Siddiqui, M.K. (2007) Velocity Measurements around a Freely Swimming Fish Using PIV. Measurement Science and Technology, 18, 96-105. http://dx.doi.org/10.1088/0957-0233/18/1/012

[105] Sakakibara, J., Nakagawa, M. and Yoshida, M. (2004) Stereo-PIV Study of Flow around a Maneuvering Fish. Experiments in Fluids, 36, 282-293. http://dx.doi.org/10.1007/s00348-003-0720-z

[106] Lauder, G.V. and Madden, P.G. (2008) Advances in Comparative Physiology from High-Speed Imaging of Animal and Fluid Motion. Annual Review of Physiology, 70, 143-163. http://dx.doi.org/10.1146/annurev.physiol.70.113006.100438

[107] Khan, L.A. (2006) A Three-Dimensional Computational Fluid Dynamics (CFD) Model Analysis of Free Surface Hydrodynamics and Fish Passage Energetics in a Vertical-Slot Fishway. North American Journal of Fisheries Management, 26, 255-267. http://dx.doi.org/10.1577/M05-014.1

[108] Chorda, J., et al. (2010) Two-Dimensional Free Surface Flow Numerical Model for Vertical Slot Fishways. Journal of Hydraulic Research, 48, 141-151. http://dx.doi.org/10.1080/00221681003703956

[109] Marriner, B.A., et al. (2014) Field and Numerical Assessment of Turning Pool Hydraulics in a Vertical Slot Fishway. Ecological Engineering, 63, 88-101. http://dx.doi.org/10.1016/j.ecoleng.2013.12.010

[110] Plymesser, K.E. (2014) Modeling Fish Passage and Energy Expenditure for American Shad in a Steeppass Fishway Using a Computational Fluid Dynamics Model. Montana State University, Bozeman.

[111] Abdelaziz, S.M.A. (2013) Numerical Simulation of Fish Behavior and Fish Movement through Passages. TUM, Lehrstuhl für Wasserbau und Wasserwirtschaft.

[112] Kim, S., et al. (2012) A Numerical Study on Hydraulic Characteristics in the Ice Harbor-Type Fishway. KSCE Journal of Civil Engineering, 16, 265-272. http://dx.doi.org/10.1007/s12205-012-0010-5

[113] Wu, C.-J. and Wang, L. (2007) Direct Numerical Simulation of Self-Propelled Swimming of 3D Bionic Fish School. Computational Mechanics, Proceedings of ISCM.

[114] Andersson, A.G., et al. (2012) A Study of the Location of the Entrance of a Fishway in a Regulated River with CFD and ADCP. Modelling and Simulation in Engineering, 2012, Article ID: 327929.

[115] Barton, A. and Keller, R. (2003) 3D Free Surface Model for a Vertical Slot Fishway. Proceedings of the XXX IAHR Congress, AUTh, Thessaloniki.

[116] Mendelson, L. and Techet, A.H. (2015) Quantitative Wake Analysis of a freely Swimming Fish Using 3D Synthetic Aperture PIV. Experiments in Fluids, 56, 135. http://dx.doi.org/10.1007/s00348-015-2003-x

[117] Saarenrinne, P., Piirto, M. and Eloranta, H. (2001) Experiences of Turbulence Measurement with PIV. Measurement Science and Technology, 12, 1904-1910. http://dx.doi.org/10.1088/0957-0233/12/11/320

[118] Westerweel, J. (2000) Theoretical Analysis of the Measurement Precision in Particle Image Velocimetry. Experiments in Fluids, 29, S003-S012. http://dx.doi.org/10.1007/s003480070002

[119] Gui, L., Longo, J. and Stern, F. (2001) Biases of PIV Measurement of Turbulent Flow and the Masked Correlation-Based Interrogation Algorithm. Experiments in Fluids, 30, 27-35. http://dx.doi.org/10.1007/s003480000131 